\title{
Study on the Relationship between Experience Quality, Co-Created Value and Users' Behavioral Intention of Making Continuous Contributions on Internet UGC Platforms
}

\author{
Ximin Duan, Liangtie Dai \\ School of Management, Jinan University, Guangzhou, China \\ Email: byronsimon@yeah.net
}

How to cite this paper: Duan, X.M. and Dai, L.T. (2018) Study on the Relationship between Experience Quality, Co-Created Value and Users' Behavioral Intention of Making Continuous Contributions on Internet UGC Platforms. Journal of Service Science and Management, 11, 267-277. https://doi.org/10.4236/jssm.2018.112019

Received: March 12, 2018

Accepted: April 25, 2018

Published: April 28, 2018

Copyright $\odot 2018$ by authors and Scientific Research Publishing Inc. This work is licensed under the Creative Commons Attribution International License (CC BY 4.0).

http://creativecommons.org/licenses/by/4.0/

\begin{abstract}
To explore the influencing factors and action mechanism of users' behavioral intention of making continuous contributions on Internet UGC platforms, the paper conducts a questionnaire survey among 574 users on Internet UGC platforms, analyzes and validates the relational model through structural equations. The research results show that experience quality has a significantly positive impact on users' behavioral intention of making continuous contributions. Consisting of pragmatic value, hedonic value and user equity, co-created value has a complete mediation in the relationship between experience quality and users' behavioral intention of making continuous contributions.
\end{abstract}

\section{Keywords}

Continuous Contribution Intention, Co-Created Value, Experience Quality, Internet UGC Platform

\section{Introduction}

With the explosive development of the Internet and mobile Internet during recent years, the interaction of Internet users has been fully reflected. Instead of only being content with simple access to information, they want to convert themselves from onlookers to participants. Therefore, the mode of user generated content (UGC) came into being. UGC means the content created by users themselves. Users display the content they create for other users to browse through the Internet platform. However, previous researches on Internet UGC 
communities mostly focus on users' behavioral intention of using behavior, whereas users' behavioral intention of making continuous contributions was rarely investigated. So, what factors have inspired the continuous development of Internet UGC platforms? In a study on Q \& A communities carried out by Jin, it was believed that the users' willingness to continue answering is the key factor that determines the sustainable development of Q \& A communities [1]. In this study, 10 practitioners and core users of Internet UGC platforms were interviewed to discuss the key factors that affect the sustainable development of Internet UGC platforms.

According to the service-oriented logic, Vargo and Lusch believe that value is co-created by both companies and customers, and value is created for themselves and companies while customers take the initiative to use relevant services [2]. Previous studies have pointed out that the perceptual evaluation of user experience influences users' psychological perception and behavioral intentional outcome [3], and co-created value influences users' behavioral intentions through streaming experiences [4], while the case study on Nike conducted by Verkat shows that co-created value can be achieved through customer experience [5]. This means that the quality of user experience on Internet UGC platforms may impact users' behavioral intention of making continuous contributions through co-created value.

In order to explore the influencing factors and mechanism of users' behavioral intention of making continuous contributions on the Internet UGC platforms, this study constructs the relational model of experience quality, co-created value and behavioral intention of making continuous contribution based on the framework of "Cognitive stage, Affective stage and Conative stage" proposed by Olive [6].

\section{Theoretical Background and Hypotheses Development}

Zeithaml suggests that product quality can be used to assess the overall superiority of a product, and it will affect the perceived value, which in turn affects customers' purchase behavior [7]. As more and more attention is given on researches on service quality, Berry argues that service quality can affect customer perception of value due to the consistency between customer experience and service quality [8]. This indicates that evaluation on quality may affect value. In the context of co-created value, Verkat carried out a case study on the Nike brand, and it is found that customer experience may stimulate customers to be engaged in co-created value so as to achieve co-created value [5]. This means that customer experience is the key to the realization of value. Measurement of customer experience or advantage may also be an important relationship that determines value. Lemke et al. define the quality of customer experience as customers' measurement of their experience or product advantages [3]. From the user's point of view, to be a loyal core user of a UGC platform, the user himself or herself must feel the usefulness of products and services provided by this 
UGC platform and get the values they need. Moreover, affecting users' use and contribution behavior, users' evaluation on the quality they perceive during the experience process can be linked with the value created by them. User experience is not just a reflection of how users feel about the practicability of products and services, but also users' psychological feelings towards the experience process. Therefore, the quality of user experience is not only related to the functional factors of users' perceived services, but also the psychological performance of users. The functional factors of the perceived services of users correspond to their use value, and users' psychological performance is closely related to their psychological value.

According to Payne et al., instead of creating and delivering value for passive users, the enterprise embed value in the process of co-creation between itself and active users, and the enterprise and users jointly create a unique experience together to realize co-created value [9]. The study by Zhang et al. revealed that in the virtual community environment, the quality of customer experience can directly stimulate the realization of co-created value [10]. In a study on virtual communities carried out by $\mathrm{Tu}$ et al., it was pointed out that the quality of user experience can motivate users and platforms to jointly create the value they need. In addition, according to their study, co-created value can be divided into pragmatic value, hedonic value and user equity [11]. Pragmatic value focuses on how users solve rational problems. According to Babin et al., as a pursuit of intentional results, pragmatic value mainly reflects whether a product or service satisfies the user's need with its functions. Stemming from the performance of products and services during application, pragmatic value is defined by evaluation on products made by users based on their preferences as well as whether the products or services satisfy users' demands. Referring to the value of gaining pleasure and spiritual enjoyment from the target object, the hedonic value has more cognitive and subjective characteristics than the pragmatic value. Non-instrumental, experiential and emotional, it is usually associated with the emotional factors of user experience, and good experience helps to improve the hedonic value [12]. As for user equity, Wang considers it as an important asset created by a company and its customers during their long-term cooperative relationship, which is reflected as value created by a long-term cooperative relationship [13]; a positive evaluation and perception of user experience can have a positive effect on important user equity such as corporate reputation and brand loyalty. To sum up, the following hypotheses were proposed:

Hypothesis 1a: The quality of user experience has a positive impact on the pragmatic value.

Hypothesis 1b: The quality of user experience positively impacts the hedonic value.

Hypothesis 1c: The quality of user experience positively affects user equity.

Referring to users' participation of making contributions on UGC platforms and the possibility of continuing such a behavior for a period of time, users' be- 
havioral intention of making continuous contributions is an important factor to explain users' participation in making contributions in the future. According to the theory of planned behavior, behavioral intention can inspire future behavior. In the original study, Zeithaml concluded that value is a cause for customers to make the purchasing decision [7]. As for the relationship between value and behavioral intention, Cronin et al. found that the value has a positive impact on repeat purchase [14]. According to the study conducted by Ha et al. on the catering industry, both pragmatic value and hedonic value can have a positive impact on behavioral intention [15]. Hyan et al. also consider that perceived value may have a positive effect on behavioral intention [16]. Tu et al. found that in virtual communities, user-generated value has a significant positive impact on users' intention of reusing [11].

In the context of co-created value, the behavior and attitude of a user may also be stimulated when his or her needs are satisfied after the user achieves both pragmatic value and hedonic value through the process of co-creating value with other users. This shows that the value co-created by users may also affect users' behaviors and attitudes. On Internet UGC platforms, users can obtain pragmatic value such as information as well as hedonic value like pleasure and spiritual enjoyment, and at the same time create user equity for these platforms. The satisfaction of functional pragmatic value becomes the basic condition for users to participate in making contributions in the future, and the realization of hedonic value based on subjective emotional experience is also a catalyst for users to make continuous contributions. As an indicator reflecting user stickiness that indirectly reveals enterprise reputation and user loyalty, user equity is even more strongly correlated with users' behavior of making continuous contributions. Therefore, the realization of user value and the formation of user equity may have a positive impact on the behaviors and attitudes of users. In summary, the following hypotheses were proposed:

Hypothesis 2a: The pragmatic value positively influences users' behavioral intention of making continuous contributions.

Hypothesis 2b: The hedonic value has a positive impact on users' behavioral intention of making continuous contributions.

Hypothesis 2c: User equity positively affects users' behavioral intention of making continuous contributions.

In the study of experiential marketing, Schmitt points out that the better the consumer's overall experience is, the more active the behavioral response is after the experience [17]. The study of Bolton et al. believes that the service experience is positively related to the decision to revisit the service [18]. Blackwell et al. emphasizes that the degree of consumer experience will affect consumers' assessment after consumption. Positive consumption experience will generate strong word-of-mouth communication. Negative consumption experience will affect the word-of-mouth of products, thereby reducing repurchases [19]. Ibranhim et al. believes that the perception experience of consumers in a shop will di- 
rectly affect the enjoyment of the experience, and will further affect the behavior after shopping [20]. Beeho et al. research found that if tourists feel satisfied with their recreation experience, they will recommend the tourist places to their friends and relatives, that is, there is a positive correlation between tourist experience and tourists' behavioral intentions [21]. Baker et al. has studied the effect of performance quality and satisfaction experience on post travel behavior intention. The results show that service quality and satisfaction experience have direct impact on behavior intention [22]. To sum up, the following hypotheses were proposed:

Hypothesis 3: The quality of user experience positively affects users' behavioral intention of making continuous contributions.

The overall hypothesis model of this study is shown in Figure 1.

\section{Research Methods}

\subsection{Measurement Indexes}

The experience quality measurement scale used in this study is based on the scale developed by Joarvitteso et al. [23] and was properly revised to adapt to different UGC platforms. Based on the study by $\mathrm{Tu}$, co-created value was divided into pragmatic value, hedonic value and user equity [11], and they were adaptively modified on this basis according to the background of this study. The scale to measure users' behavioral intention of making continuous contributions is based on the scale compiled by Bhattacherjee [24], and was re-compiled based on the research background of Internet UGC platforms as well as the conclusions gained by the interviews with 10 practitioners and core users of Internet UGC platforms. In the questionnaire design, we used the 5-point Likert scale, representing answers from "strongly disagreeing" to "strongly agreeing", which was applied to all questions. To ensure the reliability and validity of the questionnaire, we conducted a preliminary survey and received a total of 178 valid questionnaires. The Cronbach's alpha coefficient of each scale was above 0.7. Besides, some specific questions were adjusted to form the final questionnaire containing 20 questions.

\subsection{Research Process and Data Collection}

The questionnaire was amended and improved through the initial questionnaire

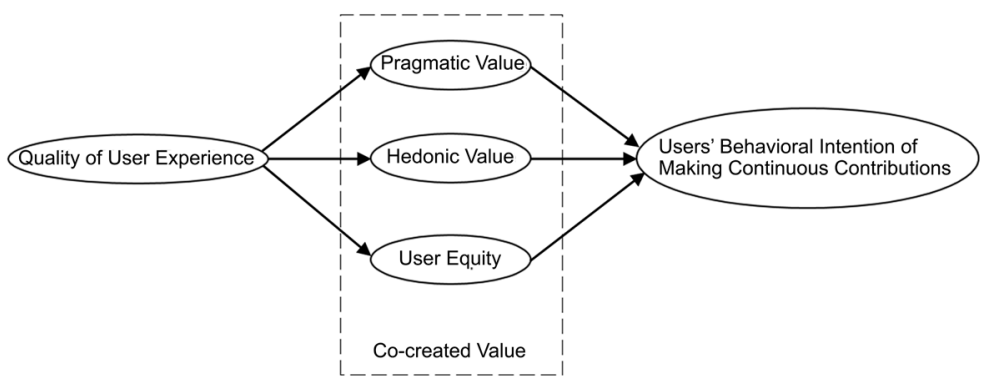

Figure 1. Diagram of the research model. 
predictive analysis before the formal questionnaire survey was carried out. Considering that the main research object of this study is the use behavior of Internet UGC platforms, the questionnaires were mainly distributed online. From November to December 2017, we distributed a total of 700 questionnaires through Zhihu, Sina Weibo, QQ, We Chat etc. and collected 514 valid questionnaires, with the effective recovery rate being $73.4 \%$. Among them, those who have used UGC platforms for more than 5 years account for $13.94 \%$; there are 24.91\% respondents who have used UGC platforms for 3 - 5 years; those who have used UGC platforms for 1 - 3 years take up 39.90\%; $12.72 \%$ respondents have used UGC platforms for less than 1 year. A total of $91.46 \%$ of the respondents had more than 3 months of experience using UGC platforms, which is well in line with characteristics of the target population to be investigated in this study.

\section{Results}

\subsection{Reliability and Validity Analysis}

SPSS 20.0 was used to conduct a statistical analysis, the results of which show that the KMO of the formal scale reaches 0.856 and passed the Bartlett's Test of Sphericity $(p<0.001)$. The commonality of all the questions and variables is above 0.5 , and the cumulative variance explained is $67.9 \%$. In this study, the Cronbach's $\alpha$ coefficient was used to measure the internal consistency of the questionnaire predictions. The Cronbach's $\alpha$ of all variables exceeds the standard value of 0.7 , and the Cronbach's $\alpha$ of the overall scale is 0.905 , indicating a good internal consistency of the scale whose reliability meets the standard requirements. The construction reliability of variables in this study ranges from 0.755 to 0.916 , which exceeds the standard value of 0.7 , indicating that this study features good construction reliability. In the validity test, the standardization factor loading of all the latent variables is above 0.5 with statistical significance, and the average value is higher than the standard value of 0.5 , indicating that the convergent validity of each variable meets the standard requirements. The correlation coefficient between the latent variables is less than the square root of the average variance of the latent variables, indicating that the discriminant validity of the latent variables meets the standard requirements.

\subsection{Confirmatory Factor Analysis}

In this study, AMOS21.0 was applied to analyze the structural equation model. A confirmatory factor analysis was performed first. According to the model fitting degree results, $X^{2} / d f$ is 1.73 , which is less than 3 , meeting the standard requirements, RMSEA is 0.038 , which is less than 0.08 , meeting the standard value requirements; $C F I$ is $0.96, I F I$ is 0.97 , and $G F I 0.97$, the fitting index of which is higher than the standard value of 0.90 . It shows that the model and data fitting results meet the requirements. 


\subsection{Hypothesis Testing}

In this study, the structural equation model was combined with the Bootstrap and Mackinnon PRODCLIN methods [25] [26] to test and analyze how the quality of user experience influence users' behavioral intention of making continuous contributions on UGC platforms and the mediation existed within, the specific test results are shown in Table 1.

The first step is to examine the overall effect of the quality of user experience on users' behavioral intention of making continuous contributions $(\mathrm{X} \geq \mathrm{Y})$. The $\mathrm{Z}$ value of the total effect is 4.29 , which is greater than 2.58 and significant at the 0.01 level; in the test carried out with the Bootstrapping method, the confidence interval does not include 0 , so the test results prove that the quality of user experience has a significant overall effect on users' behavioral intention of making continuous contributions $(\mathrm{X} \geq \mathrm{Y})$.

The second step is to test the indirect effect of the quality of user experience on users' behavioral intention of making continuous contributions $(\mathrm{X} \geq \mathrm{Y})$. The $\mathrm{Z}$ value of the indirect effect is 1.973 , which is greater than 1.96 and significant at the 0.05 level; in the test carried out using the Bootstrapping method, the confidence interval does not include 0 , so the test results prove that the quality of user experience as a significant indirect effect on users' behavioral intention of making continuous contributions $(\mathrm{X} \geq \mathrm{Y})$.

The third step is to examine the direct effect of the quality of user experience on users' behavioral intention of making continuous contributions $(\mathrm{X} \geq \mathrm{Y})$. The $\mathrm{Z}$ value of the direct effect is -1.11 , which is greater than -1.96 and less than 1.96 , indicating an insignificant correlation between the two; in the test carried out with the Bootstrapping method, 0 is included in the confidence interval, so the test results demonstrate that the quality of user experience does not have a significant direct effect on users' behavioral intention of making continuous

Table 1. Variable Relationship Test (Standardization).

\begin{tabular}{|c|c|c|c|c|c|c|c|c|c|}
\hline \multirow{3}{*}{ Variable } & \multirow{3}{*}{ Estimate } & \multirow{2}{*}{\multicolumn{2}{|c|}{$\begin{array}{l}\text { Product of } \\
\text { Coefficients }\end{array}$}} & \multicolumn{4}{|c|}{ Bootstrapping } & \multirow{2}{*}{\multicolumn{2}{|c|}{$\begin{array}{l}\text { Mackinnon } \\
\text { PRODCLIN2 } \\
\text { 95\% CI }\end{array}$}} \\
\hline & & & & \multicolumn{2}{|c|}{$\begin{array}{l}\text { Bias-Corrected } \\
95 \% \text { CI }\end{array}$} & \multicolumn{2}{|c|}{ Percentile 95\% CI } & & \\
\hline & & SE & Z & Lower & Upper & Lower & Upper & Lower & Upper \\
\hline \multicolumn{10}{|c|}{ Total Effects } \\
\hline$X \geq Y$ & 0.335 & 0.078 & 4.29 & 0.175 & 0.48 & 0.181 & 0.485 & & \\
\hline \multicolumn{10}{|c|}{ Direct Effects } \\
\hline$X \geq Y$ & -0.456 & 0.411 & -1.11 & -1.35 & 0.227 & -1.346 & 0.23 & & \\
\hline \multicolumn{10}{|c|}{ Indirect Effects } \\
\hline$X \geq Y$ & 0.791 & 0.401 & 1.973 & 0.149 & 1.697 & 0.137 & 1.676 & & \\
\hline$X \geq S Y \geq Y$ & & & & & & & & 0.02 & 0.437 \\
\hline $\mathrm{X} \geq \mathrm{XL} \geq \mathrm{Y}$ & & & & & & & & 0.15 & 1.45 \\
\hline $\mathrm{X} \geq \mathrm{ZC} \geq \mathrm{Y}$ & & & & & & & & 0.147 & 0.544 \\
\hline
\end{tabular}


contributions $(\mathrm{X} \geq \mathrm{Y})$. It indicates that the mediation in this model is a complete mediation.

The fourth step is to examine whether there is a suppression effect. The direct effect $(-0.456)+$ the indirect effect $(0.791)=$ the total effect $(0.335)$, meeting the conditions of the mediating model.

The fifth step is to test specific indirect effects. 1) The specific indirect effect that the quality of user experience impacts users' behavioral intention of making continuous contributions ( $\mathrm{X} \geq \mathrm{SY} \geq \mathrm{Y}$ ) through pragmatic value is tested. The confidence interval tested by the Mackinnon PRODCLIN2 method is [0.02, 0.437 ] which does not contain 0 , indicating that there is a specific indirect effect that the quality of user experience impacts users' behavioral intention of making continuous contributions ( $\mathrm{X} \geq \mathrm{SY} \geq \mathrm{Y}$ ) through pragmatic value. 2) The specific indirect effect that the quality of user experience impacts users' behavioral intention of making continuous contributions $(\mathrm{X} \geq \mathrm{XL} \geq \mathrm{Y})$ through hedonic value is tested. The confidence interval tested by the Mackinnon PRODCLIN2 method is $[0.15,1.45]$ which does not contain 0 , indicating that there is a specific indirect effect that the quality of user experience impacts users' behavioral intention of making continuous contributions $(\mathrm{X} \geq \mathrm{XL} \geq \mathrm{Y}$ ) through hedonic value. 3) The specific indirect effect that the quality of user experience impacts users' behavioral intention of making continuous contributions $(\mathrm{X} \geq \mathrm{ZC} \geq \mathrm{Y})$ through user equity is tested. The confidence interval tested by the Mackinnon PRODCLIN2 method is $[0.147,0.544]$ which does not contain 0 , indicating that there is a specific indirect effect that the quality of user experience impacts users' behavioral intention of making continuous contributions ( $\mathrm{X} \geq \mathrm{ZC} \geq \mathrm{Y}$ ) through user equity. Therefore, it can be determined that this model is a parallel three-factor complete mediation model.

Hypotheses 1a, 1b, 1c, 2a, 2b, 2c and 3 were verified on the "knowledge-based" Internet UGC platforms.

\section{Conclusions and Suggestions}

\subsection{Conclusions}

With Internet UGC platforms as the research background, a model showing the relationship between the quality of user experience, co-created value and users' behavioral intention of making continuous contributions was established, and the research hypotheses were tested through empirical research. The conclusion is drawn that the quality of user experience is a key determinant of users' behavioral intention of making continuous contributions on Internet UGC platforms. That is to say, the higher the quality of user experience, the stronger users' intention of making continuous contributions. In particular, the co-created value plays a complete mediating role during the process where users' behavioral intention of making continuous contributions is affected by the quality of user experience. In other words, the quality of user experience does not directly affect users' behavioral intention of making continuous contributions. Instead, only 
after users develop a perception of the value of their experience can the quality of user experience influence users' behavioral intention. In the use of Internet UGC platforms, the quality of user experience online has become an important index for users to measure whether the services are satisfactory. When users perceive the online experience provided by UGC platforms as attractive and efficient, user satisfaction will constantly rise, so as to stimulate users to actively participate in sharing, exchanging, searching, browsing and thereby obtaining more pragmatic value. Fun and relaxed experience allows users to gain pleasant and enjoy able psychological satisfaction, and thus obtain a higher level of hedonic value. High-quality experience narrows the distance between users and the platform and enhances users' understanding and recognition of the platform, which helps the platform gain more user equity. Values co-created by users and the platform, e.g. pragmatic value, hedonic value and user equity, further promote the generation of users' behavioral intention of making continuous contributions.

\subsection{Practical Suggestions}

By discussing how the quality of user experience, co-created value and users' behavioral intention of making continuous contributions influences each other on UGC platforms, this study proposed the following positive suggestions for Internet UGC platform sat a practical level.

First of all, the quality of user experience is an important factor that determines users' intention of making continuous contributions. Quality of user experience refers to users' perception and evaluation of the goodness or advantages of the products or services they experience. UGC platforms should attach importance to user experience by providing an attractive, concise and efficient user interface, provide personalized services for users and offer high-quality UGC to improve the quality of user experience. More abundant materials should be provided for creation, timely feedback should be given on users' contribution behavior, operation habits of users should be respected, and reminders ought to be set for each process switch, so as to improve the quality of user experience when users contribute content.

Second, co-created value has an important impact on users' intention of making continuous contributions. Co-created value refers to the value jointly created by users through exchange, interaction, contribution and sharing on UGC platforms. UGC platforms should lay emphasis on co-creating value with users, provide a favorable environment and functions needed by the exchange and interaction between users and users as well as that between users and platforms, clarify and optimize the platform standards, provide a good atmosphere for the exchange and interaction among users. Besides, contributions and sharing made by users should be encouraged and timely responded. In addition, UGC platforms are supposed to improve soft services, guarantee both quality and efficiency of the content on the premise of providing users with adequate room to bring their creativity into full play, guide users to participate in 
co-created value and achieve co-created value at a higher level.

\section{References}

[1] Jin, X.-L. (2009) Understanding the Sustainability of Online Question Answering Communities in China: The Case of "Yahoo! Answers China". Ph.D. Thesis, University of Science and Technology of China, Beijing.

[2] Lusch, R.F and Vargo, S.L. (2006) Service-Dominant Logic. Reactions, Reflections and Refinements. Marketing Theory, 6, 281-288.

https://doi.org/10.1177/1470593106066781

[3] Lemke, F., Clark, M. and Wilson, H. (2011) Customer Experience Quality: An Exploration in Business and Consumer Contexts Using Repertory Grid Technique. Journal of the Academic and Marketing Science, 39, 864-869. https://doi.org/10.1007/s11747-010-0219-0

[4] Tu, J.-B., Zhang, X.-R. and Tao, X.-B. (2015) Research on the Relationship between Involvement, Co-Created Value and Behavioral Intention in Non-Trading Virtual Community. Collected Essays on Finance and Economics, 11, 88-95.

[5] Ramaswamy, V. (2008) Co-Creating Value through Customers Experiences the Nike Case. Strategy and Leadership, 36, 9-14. https://doi.org/10.1108/10878570810902068

[6] Oliver, R.L. (1999) Whence Consumer Loyalty. Journal of Marketing, 63, 33-34. https://doi.org/10.2307/1252099

[7] Zeithaml, V.A. (1988) Consumer Perceptions of Price, Quality, and Value: A Means-End Model and Synthesis of Evidence. Journal of Marketing, 52, 2-22. https://doi.org/10.2307/1251446

[8] Berry, L.L., Carbone, L.P. and Haeckel, S.H. (2002) Managing the Total Consumer Experience. MIT Sloan Management Review, 43, 85-89.

[9] Payne, A., Storback, K., Frow, P. and Knox, S. (2009) Co-Creating Brands: Diagnosing and Designing the Relationship Experience. Journal of Business Research, 62, 379-389. https://doi.org/10.1016/j.jbusres.2008.05.013

[10] Zhang, M.-L., Tu, J.-B. and Wang, C.-C. (2009) Research on Relations between Customer Experience Quality and Co-Creation Value Based on the View of Generalized Virtual Economy. Research on the Generalized Virtual Economy, 4, 45-54.

[11] Tu, J.-B. (2016) The Formation of Virtual Community Co-Creation Value and Its Influencing Factors. Intellectual Property Press LLC, Beijing.

[12] Babin, B.J., Darden, W.R. and Griffin, M. (1994) Work and Fun: Measuring Hedonic and Utilitarian Shopping Value. Journal of Consumer Research, 20, 644-656. https://doi.org/10.1086/209376

[13] Wang, Y.-G. (2005) Customer Resource Management-Assets, Relationships, Values and Knowledge. Peking University Press Co., Ltd., Beijing.

[14] Cronin, J.J. and Morris, M.H. (1989) Satisfying Customer Expectation: The Effect on Conflict and Repurchase Intentions in Industrial Marketing Channels. Journal of the Academy of Marketing Science, 17, 41-49. https://doi.org/10.1007/BF02726352

[15] Ha, J. and Jang, S. (2010) Perceived Values, Satisfaction, and Behavioral Intentions: The Role of Familiarity in Korean Restaurants. International Journal of Hospitality Management, 29, 2-13. https://doi.org/10.1016/j.ijhm.2009.03.009

[16] Hyan, S.S., Kim, W. and Lee, M.J. (2011) The Impact of Advertising on Partrons' Emotional Response, Perceived Value, and Behavioral Intentions in The Chain Restaurant Industry: The Moderating Role of Advertising-Induced Arousal. Inter- 
national Journal of Hospitality Management, 30, 689-700. https://doi.org/10.1016/j.ijhm.2010.10.008

[17] Schmitt, B.H. (1999) Experiential Marketing: How to Get Customers to Sense, Feel, Think, Act, Relate to Your Company and Brands. The Free Press, New York.

[18] Bolton, R.N., Kanna, R.K. and Bramlett, M.D. (2000) Implications of Loyalty Program Membership and Service Experiences for Customer Retention and Value. Journal Academy Marketing Science, 28, 95-108. https://doi.org/10.1177/0092070300281009

[19] Blackwell, R.D., Miniard, P.W. and Engel, J.F. (2001) Consumer Behavior. 9th Edition, Hartcourt, Orlando FL.

[20] Ibrahim, M.F. and Ng, C.W. (2002) Determinants of Entertaining Shopping Experiences and Their Link to Consumer Behavior: Case Studies of Shopping Centers in Singapore. Journal of Leisure Property, 2, 338-357. https://doi.org/10.1057/palgrave.rlp.5090155

[21] Beeho, A.J. and Prentice, R.C. (1997) Conceptualizing the Experiences of Heritage Tourists: A Case Study of New Lanark World Heritage Village. Tourism Management, 18, 75-87. https://doi.org/10.1016/S0261-5177(96)00103-3

[22] Baker, D.A. and Crompton, J.L. (2000) Quality, Satisfaction and Behavioral Intentions. Annals of Tourism Research, 27, 785-804. https://doi.org/10.1016/S0160-7383(99)00108-5

[23] Vittersø, J., Vorkinn, M., Vistad, O.I. and Vaagland, J. (2000) Tourist Experiences and Attractions. Annals of Tourism Research, 27, 432-450.

[24] Bhattacherjee, A. (2001) Understanding Information Systems Continuance: An Expectation-Confirmation Model. MIS Quarterly, 25, 351-370. https://doi.org/10.2307/3250921

[25] Preacher, K.J. and Hayes, A.F. (2008) Asymptotic and Resampling Strategies for Assessing and Comparing Indirect Effects in Multiple Mediator Models. Behavior Research Methods, 40, 879-891. https://doi.org/10.3758/BRM.40.3.879

[26] MacKinnon, D.P., Fritz, M.S., Williams, J. and Lockwood, C.M. (2007) Distribution of the Product Confidence Limits for the Indirect Effect Program PRODCLIN. Behavior Research Methods, 39, 384-389. https://doi.org/10.3758/BF03193007 